\title{
Moroccan mothers' involvement in dialogic literary gatherings in a Catalan urban primary school: Increasing educative interactions and improving learning
}

\author{
Lena de Botton \\ University of Barcelona, Spain \\ Sandra Girbés \\ University of Barcelona, Spain \\ Laura Ruiz \\ University of Edinburgh, UK \\ Itxaso Tellado \\ University of Vic, Spain
}

\begin{abstract}
This article analyses a case study on Moroccan mothers' involvement in the Dialogic Literary Gathering (DLG) in an urban primary school in Catalonia (Spain). DLG is a dialogic learning environment that improves reading skills and communicative abilities and promotes school-community links. This activity has been identified in previous European Union (EU)-funded large scale research, the INCLUD-ED project, as a successful educational action. Children's results in standardised tests reported a significant improvement in communicative skills over the academic year. The case study highlights evidences on how this action contributed to transform family interactions at home. Discussions about classic works of literature were transferred to the child-parent interactions and were part of their daily lives. According to the data analysed, this experience affected mothers' and children's motivation to read and helped migrant mothers to improve the language acquisition of the host country. Mothers confirmed becoming more able to understand the schoolwork of their children and they felt more confident to help them with their homework.
\end{abstract}

Keywords

Community, dialogic learning, family involvement, poverty, school, successful educational action

\section{Introduction}

This article analyses the results of a case study on Moroccan mothers' involvement in the Dialogic Literary Gathering (DLG) in an urban primary school in Catalonia (Spain). Children's results in standardised tests in this school reported a significant improvement in communicative skills over the academic year. The case study presented in this article shows how the Moroccan mothers' involvement in the DLG contributed to transforming the interactions between parents and children at home. Discussions about classic works of literature were transferred to the child-parent interactions and were part of their daily lives. According to the data analysed, these experiences affected mothers' and children's motivation to read and helped migrant mothers to improve the Language acquisition of the host country. Mothers stated that they had become more able to understand the schoolwork of their children and that they felt more confident to help them with their homework. Before presenting the theoretical position, methodology and results of this case study, the article outlines the origins of DLG, its relationship with the Centre of Research in Theories and Practices that Overcome Inequalities (CREA) of the University of Barcelona and with the School as Learning Communities project. The first DLG was formed in 1980 in the Adult School of La Verneda-Sant Martí, in a workingclass district of Barcelona, influenced by the workers' literary circles which were being formed before Franco's dictatorship (Giner, 2011). In this gathering, people who had just become literate and with a low educational level read and discuss classic works of world literature. In a dissertation about the DLG at the University of Harvard, a researcher from the National Center for the Study of Adult Learning and Literacy reported what one participant told her, to her amazement: 'Look, the people understand it all, and the better it is written, the better they understand' (Soler, 2001). After the end of the dictatorship and during the process of transition to democracy, a movement of neighbours in the La Verneda district demanded a space for education and access to culture for this community. The Adult School of La Verneda-Sant Martí was finally established in 1978. Since then and up to the present day, this school has been characterised by its democratic management and by taking account of the most up-to-date findings of the international research community concerning education and social justice. The school has been the subject of multiple investigations and publications (Racionero \& Serradell, 2005; Sánchez-Aroca, 1999; Tellado, Serrano, \& Portell, 2013) and has been visited by prestigious international intellectuals and researchers including Paulo Freire.

Among the neighbours who set up this school was Ramón Flecha, who in 1992 established CREA at the University of Barcelona. Over a period of 30 years, the DLG and the educational model of the Adult School of La Verneda-Sant Martí have spread to around 200 educational establishments, including nurseries, primary and secondary schools and adult education in various countries of Europe, North America and Latin America, under the general title of Schools as 
Learning Communities (Ríos, Herrero, \& Rodríguez, 2013). During this period, there has been a process of continuous investigation, deepening and development of different aspects of the Learning Communities project, always with the rigour which the international research community expects and with the aim of making a contribution to social change. Likewise, as a public centre for research, it has always been generous and disinterested in offering the Schools as Learning Communities project to whoever wishes to adopt and develop it. In this sense, the research centre has celebrated the participation of groups, people, administrations and so on who wanted to work in a scientific and rigorous manner. In the early years, it was CREA which carried out the systematic assessment of all the centres of nursery, primary and secondary education which wanted to become a 'Community of Learning'. Thus, the research centre placed all its knowledge at the disposal of others. This case study about the DLG with Moroccan mothers took place in a School as Learning Community in one of the most deprived districts of a town near to Barcelona.

\section{Theoretical framework}

As is well known, research studies of social reproduction since 1970 have analysed the link between student achievement and the family's educational level (Baudelot \& Establet, 1971; Bourdieu \& Passeron, 1970; Bowles \& Gintis, 1976). This analysis has helped explain how the social capital of families is inherited by the children and how social context determines academic performance. However, these theories failed to take into account other fundamental factors which have a great influence and which can transform this relationship. If the analysis focuses only on the family's educational level, the research studies end up by legitimising this reality and neglecting any possibility of changing it.

Social reproduction theories have decisively influenced international investigations. For example, studies such as Progress in International Reading Literacy Study (PIRLS) and Programme for International Student Assessment (PISA) collect data on the number of books in the children's homes, or on the number of hours which the children and their families devote to reading. These data offer information about the educational resources in the home but do not provide knowledge about actions which contribute to improving the children's academic results. This runs the risk of concluding that simply increasing the number of books in each home will improve educational success. Or if the analyses are restricted to looking at the family's educational level, we run the risk of thinking that it will be impossible to help children learn successfully until the general qualification levels of society go up - a position of impossibility. To take another example, during PIRLS 2006, children in the fourth grade of primary school were asked, 'Are any of the following programs and services available at your school site for children and families?' Possible answers include the following: 'Adult literacy programs for native language speakers, adult literacy programs for non-native language speakers, and education programs for parents (including programmes such as classes on child development and education on being a parent)'. Although PIRLS has added some question related to the training or educational programmes in which the parents might be participating, unfortunately, the report does not show whether there is actually a link between students' academic performance and the family's participation in these programmes (INCLUD-ED Consortium, 2009).

As we also know, from the sociocultural perspective and that of dialogical learning (Bakhtin, 1981; Sinha, 2013; Vygotsky, 1962) by taking action to transform the sociocultural context, it is possible to improve the learning processes of children, and especially those in the most unfavourable circumstances. The interactions between these children and all the people around them, including teachers, families and peers, are the key (Tran, 2014). An increase in the cultural and educative interactions of the children with these social agents, especially with family members, contributes to an improvement in children's achievement (Rogoff, Goodman Turkanis, \& Bartlett, 2001). It is generally understood that educational action alone is insufficient to abolish poverty. However, it has also been demonstrated that some initiatives can help disrupt the pattern whereby schooling tends to reproduce disadvantage. In disadvantaged contexts when mothers access education, this contributes to breaking the cycle of reproduction whereby poverty is transmitted down the generations. Mothers' participation in educational activities is a key because they provide inspiration to their children and monitor their learning (Sen, 1999). For this reason, schools can become agencies for social justice (Smyth \& Wrigley, 2013).

Among other things, the school can create cultural and educational spaces for families, and enable parents and other relatives to enhance the quality of their cultural and educative interactions with their children. It is simply not good enough for researchers to confirm the existence of a link between the parents' education level and the child's success at school. The INCLUD-ED Project (Flecha, 2006-2012) has gone beyond this. This European Union (EU)-funded project has identified what specific actions promote more cultural and educative interactions between students and family members and consequently open up learning opportunities for all, especially in disadvantaged backgrounds, leading to an improvement in children's school achievement. The evidence collected by this International research study has identified educational actions which can maximise achievement and social cohesion across many different contexts (Flecha \& Soler, 2013). Among these actions, we find DLGs. The DLG is a dialogic learning environment based on dialogic 
models of teaching and learning. It draws on the sociocultural theory of Vygotsky $(1962,1978)$. It also shares basic principles of Freire's (1973) 'culture circles' and of dialogic learning (Flecha, 2000). The DLGs based on these theories and practices were created to overcome the fixedness of reproduction theory and the dèficit perspectives which end up preventing adults of disadvantaged social classes from accessing this type of culture (Bourdieu, 1984).

\section{Methodology}

The following case study focuses on Moroccan mothers' involvement in a DLG in an urban primary school in a low socioeconomic status (SES) neighbourhood in Catalonia, Spain. This case study answers two research questions: (1) How mothers' involvement in the DLGs is contributing to increasing the educative interactions between families and children? (2) How these interactions are contributing to improving children's learning? The case study is based on communicative observations during 15 sessions of the Moroccan mothers' DLG during the 2013-2014 school year, as well as interviews and informal conversations before and after these sessions. A total of 20 Moroccan mothers were involved, with children in preschool and different primary grades at the school. In addition, some have babies who aren't yet at nursery or children who are already at secondary school but who attended primary school here. As far as the socio-educative level is concerned, the majority come from poor rural areas of Morocco and very few from urban areas. Most have not even gained a basic school qualification, and some of them were not literate in any language before becoming involved in this programme. The interviews and conversations, both individual and group, with these women served to identify how the DLG was having an impact on the interactions between their families and children and improving learning.

As regards communicative observations, it is important to state that, following the principles of 'communicative methodology' (Puigvert, Christou, \& Holdford, 2012), the person observing and those being observed are on an equal level in interpreting the actions, attitudes, motivation, skills and non-verbal language. Both parties make an interpretation and seek to reach a consensus. This is why we call it communicative observation. The school is located in a low-SES neighbourhood and is composed of pupils belonging to minority groups (more than $80 \%$ ), including immigrants, mostly from Morocco. Many of the parents have no basic education, some have not finished primary school and a quarter have completed either basic education or primary school. Only a small percentage has completed vocational training or an upper secondary education. This case study has been selected because it is located in a lowSES neighbourhood and the school has improved its academic results in recent years. One of the indicators of success is the improvement in the proportion of fourth-grade students who achieve the basic reading competence.

This school has been operating as a Learning Community and implementing successful educational actions since the 2001-2002 school year. Over the past 10 years, a significant improvement has been seen in the school, both in relation to the academic results of the pupils and in the school's relationship with the community, as it has become a space which is helping to include the richness of diverse people in the neighbourhood. In the same period, the school has seen an increase in immigrant children which is much greater than average for Catalan pre-primary and primary schools. In the 2001-2002 school year, immigrant pupils in the school were around 12 percent of the total, and this percentage reached 46 percent in 2006-2007, whereas in Catalonia in 2006-2007, the overall percentage was slightly above 10 percent. In just 5 years, while the proportion of immigrant students increased, the children who reached the basic reading competence increased from 17 percent to 85 percent. This evidence demonstrates that it is not the characteristics of the students, or of their families or the neighbourhood, which explain the results they achieve; instead, it is the actions being implemented (INCLUD-ED Consortium, 2011; Valls \& Kyriakides, 2013).

\section{Brief history and functioning of the DLG with Moroccan mothers}

The DLG with Moroccan mothers emerged from a group of mothers who had been taking part in a Spanish and Literacy course in their children's primary school. After gaining basic skills in Spanish, they wanted to improve these skills by doing another kind of activity. The school decided on an activity which had proven successful in other schools with parents as well as children, namely, the DLG.

The gathering started in $\mathbf{2 0 1 0}$ with just a few mothers, and the number of participants has been increasing over the years. Now they are around 20. They meet once a week for 2 hours to discuss what they had agreed to read at home. This increase in numbers is due to mothers encouraging others to take part. The atmosphere of trust created by this reading circle, between the women and the volunteers facilitating it, has also been important. In this gathering, they have read books such as the Arabian Nights, Shakespeare plays and Spanish classics such as Lorca. In the words of one mother, we can see how it has been possible to overcome the barriers imposed by reproduction theories which block access to this type of culture by people of a low socioeconomic level: I really encourage other mothers to take part in these circles. I tell them not to throw away an opportunity. 
Reading the classics of world literature isn't difficult. Everybody can read them. The themes which these books deal with are profound but we connect them with our everyday experience. It's very easy: everybody choose a paragraph which they have read at home and says why they have chosen it. Sharing our paragraphs with each other gets us into a debate. The classic themes of world literature help the whole of humanity to move forward. whatever our country or religion might be, the themes are common to all. The women decide which book they are going to read next. One of the first was the Arabian Nights.

They chose to read it because it was easy to connect to the popular culture of Arab countries, with important themes in the everyday lives of these women. These mothers read agreed pages at home during the week. While reading, they identify one or several paragraphs which they want to highlight for some reason. Once in the circle, the facilitator asks who has paragraphs to share. The participants who wish to raise their hand to ask for their turn. The first mother reads her paragraph and says why she has chosen it. These reflections generally relate the book with daily life, memories, interests and concerns. Once the first woman has read a paragraph aloud, the others join in a discussion about this paragraph. The opinions are shared in an egalitarian dialogue, that is, all the opinions are respected and no one tries to dominate. The aim is not to arrive at agreement on the different interpretations but to open a dialogue so that different views can be shared. When the discussion about a paragraph has finished, another woman reads hers, and the discussion beguins again. The role of the facilitator is important. She has to try to create an atmosphere in which everyone feels capable of learning and of contributing their knowledge and experience. In this way, all the women become creators of culture.

Classic works of world literature help these women to share reflections, feelings and opinions on the great universal themes of mankind: on love, war, social relations and everyday lives. The depth of these discussions, in an atmosphere of respect and trust, leads the mothers to develop links of friendship and to strengthen the school as a learning community. This is how another mother puts it, Taking part in this gathering has created real friendship among us. We have got to know each other more and turned into friends. Before taking part we didn't used to talk to each other much. When we saw each other around the neighbourhood, because we were Moroccan we would great each other with 'As-salamu alaykum', 'Wa alaykumu as-salam', but nothing more.

\section{Findings}

The case study presented here has sought to answer two research questions:

(1) How mothers' involvement in the DLGs is contributing to increasing the educative interactions between famílies and children? (2) How these interactions are contributing to improve learning?

More specifically, we have reached four main findings:

(1) the DLG has contributed to a transformation of interactions between parents and children at home,

(2) the DLG has affected mothers' and children's motivation to read,

(3) it has helped migrant mothers to improve the language acquisition of the host country and

(4) mothers stated that they had become more able to understand the schoolwork of their children and they felt more confident to help them with their homework.

Here is our evidence and thinking. The first issue is how discussions about classic works of literature were transferred to the child-parent interactions and became part of their daily lives. The discussions about world classics which arose from the literary circle often appeared again in domestic conversations. Women would discuss the themes relating to everyday life from reading the books to events in their own lives.

Following Freire's (1973) recommendations, the reading circle isn't only concerned with reading the text, but through reading and debate, the wider context is also 'read'. For example, one of the mothers we interviewed explained to her children at dinner that they were reading the Arabian Nights. This mother explained to them the importance of this book in the history of literature, who was Princess Scheherezade, and how she succeeded in preventing the sultan from killing more women each night. In turn, the reflections about gender violence or about the intelligence and courage of some women were shared among the whole family at dinner. One mother explained it in this way, Now during dinner we speak about the books we read in the gathering. I explain to my children and my husband some of the debates we have been having in the gathering. 
Also things about the books we read. When mothers read and discuss literary classics in DLGs, this contributes to creating new educational expectations which have a direct impact on the family learning environment. The gatherings help to transform family relationships, increasing the confidence of mothers who have little formal education themselves, and changing the interactions at home: parents and children engage in dialogue about the books they are reading. This represents an increase in the number and kind of academic interactions in the home setting.

Second, another of the findings is that when non-academic mothers participate in this literacy activity, they create new reading practices, cultural roles and models for interaction that influence their children's learning and thus their academic performance. According to the data analysed, these experiences have affected mothers' and children's motivation to read. Mothers have begun to read with their children at home. Both mothers and children enjoy reading together. In this school, children are also participating in a literary gathering in Spanish language classes. One of the mothers participating in the gathering explains how her 9-year-old daughter is fond of reading, and they now read together the books of the gathering:

Before we did not have books at home. Now every day before going to sleep we read together the book of the gathering or other stories. My daughter is fond of reading and she not only reads the book of the gathering, she loves reading and she does not stop reading! She is also pleased that I attend the mothers' gathering. Children take pride in the fact that their mothers are taking part in a literary gathering. Besides, the fact that the mothers are inside the school generates greater motivation for reading and for learning among their children. The mothers' involvement contributes to the children's positive feelings about school and the importance of learning. One of the mothers explained in an interview: 'My children are delighted that we are all in the school. They wear a big smile! They are really excited about it!' From an early age, the children are seeing their mothers in a new light. Mothers of very young children take them along to the gathering. In one of the interviews, a mother explained how it was possible to reconcile her family life with the gathering because she can take part in it while her older children are in school and even take the little one with her: 'We are there with our children. This works really well'.

The third finding is that the DLG is helping migrant mothers to improve their Spanish Language skills. The mothers explained in interviews how their acquisition of Spanish had speeded up. The dialogic mode of the gatherings accelerates learning. Some of them explained that when they started taking part in the group, they knew a little Spanish but that reading the agreed pages every week, preparing their contribution, reading a paragraph aloud and explaining their interest in it to others all have contributed to a rapid improvement in their use of Spanish. One said, 'Reading these books and discussing them, we learn Spanish much faster' and the other added, 'Personally I like it because I learn that way, I relate to people and improve my Spanish'. The result is that the mothers who are learning Spanish, including those who have just become literate, read and enjoy classical works of world literature, consolidating their Spanish more each time, including speaking, reading and writing skills. Finally, in the data, there is evidence of mothers who became better able to understand the schoolwork of their children. One of the mothers explained, 'Now I can understand my son's homework more. I can read the exercises with him and help him'. Thus, the mothers became empowered to help them with their homework.

This empowerment creates new dynamics at home. Some of the mothers explain how they can now help their children with homework: 'We learn a lot in the circle. Now it's easiest to help them with their homework'.

\section{Conclusion}

In order to rethink how to break the cycle whereby social and educational inequality is reproduced, it is essential to go beyond analysing the connection between the educational level of parents with children's achievement. We need to provide new answers by putting on new lenses. New investigations are needed to make possible, and analyse, actions which contribute to raising the educational level of the parents, particularly those with low socioeconomic backgrounds. For this reason, research is necessary which analyses how these actions contribute to improving learning and academic results for the children. The INCLUD-ED project contributed to this, and DLGs are one of these actions. Our case study about the DLG involving Moroccan mothers provides some answers to the two research questions: (1) Whether DLGs help to increase the cultural and educative interactions between families and children? (2) How these interactions contribute to improve learning?

This particular DLG shows how theories of social reproduction can be transcended. These Moroccan mothers with low SES read and enjoy classics of world literature, a pleasure which is normally assumed to belong only to a small cultural elite. 
At the same time, this experience shows how a school can 'make the difference' and contribute towards breaking the cycle of poor educational results and the reproduction of social inequality, and as a consequence prevent situations of poverty.

The mothers who arrived in this Catalonian town without knowing the language of their host country have speeded up their learning of Spanish, including speaking, reading and writing skills. Their participation in the DLG is contributing to enhancing the educative and cultural interactions in their homes.

They take the discussions and debates from the literary circle into mealtime conversations with their children and partners, so that discussing cultural and social themes becomes a normal domestic activity, as is the case at the dinner tables of intellectuals. The mothers' and their children's motivation for reading and learning increases, and the mothers start to see themselves as capable of helping children with schoolwork. Activities such as DLGs with mothers can contribute to their children successfully completing primary education and facing up to the demands of secondary school. For the first time in this school, mothers and children have new expectations on how the school can improve their lives.

\section{Notes}

1. Centre of Research in Theories and Practices that Overcome Inequalities (CREA) official website http:// creaub.info/.

2. Schools as Learning Communities is a project based on a set of successful educational actions aimed at social and educational transformation. This educational model is consistent with the International scientific theories which emphasise two key factors for learning in today's society: interactions and community involvement. Please keep in mind that the number of Schools as Learning Communities increases each year. More information is available on Schools as Learning Communities (Comunidades de Aprendizaje) official website http://utopiadream.info.

3. The Government of Catalonia implements evaluations of basic skills acquired in the fourth grade of Primary Education.

\section{References}

Bakhtin, M. (1981). The dialogic imagination. Austin: University of Texas Press.

Baudelot, J. P., \& Establet, R. (1971). L'ecole capitaliste en France. Paris, France: Maspero.

Bourdieu, P. (1984). Distinction: A social critique of the judgment of taste. Cambridge, MA: Harvard University Press.

Bourdieu, P., \& Passeron, J. C. (1970). La reproduction. Paris, France: Les Éditions de Minuit.

Bowles, S., \& Gintis, H. (1976). Schooling in capitalist America. New York, NY: Basic Books.

Flecha, R. (2000). Sharing words: Theory and practice of dialogic learning. Lanham, MD: Rowman \& Littlefield.

Flecha, R. (2006-2012). INCLUD-ED: Strategies for inclusion and social cohesion in Europe from education (6th

Framework Program, Citizens and Governance in a Knowledge-based Society. Grant agreement: CIT4-CT-2006028603).

Brussels, Belgium: Directorate General for Research, European Commission

Flecha, R., \& Soler, M. (2013). Turning difficulties into possibilities: Engaging Roma families and students in school

through dialogic learning. Cambridge Journal of Education, 43, 451-465. doi:10.1080/0305764X.2013.819068

Freire, P. (1973). Education for critical consciousness. New York, NY: Seabury.

Giner, E. (2011). Amistad deseada. Aportaciones de Jesús Gómez y Ramón Flecha que están acercando la

realidad a nuestros sueños [The desired friendship: Contributions from Jesús Gómez and Ramón Flecha

that are bringing our dreams to reality]. Barcelona, Spain: Hipatia.

INCLUD-ED Consortium. (2009). Actions for success in schools in Europe. Brussels, Belgium: European

Commission.

INCLUD-ED Consortium. (2011). Report 9: Contributions of local communities to social cohesion. Brussels, Belgium:

European Commission. 
Puigvert, L., Christou, M., \& Holdford, J. (2012). Critical communicative methodology: Including vulnerables voices in research through dialogue. Cambridge Journal of Education, 42, 513-526. doi:10.1080/0305764X.2012.733341 Racionero, S., \& Serradell, O. (2005). Antecedentes de las comunidades de Aprendizaje [Learning communities background]. Educar, 35, 29-39. Retrieved from http://educar.uab.cat/article/view/211.

Ríos, O., Herrero, C., \& Rodríguez, H. (2013). From access to education: The revolutionary transformation of schools as learning communities. International Review of Qualitative Research, 6, 239-253.doi:10.1525/irqr.2013.6.2.239

Rogoff, R., Goodman Turkanis, C., \& Bartlett, L. (2001). Learning together: Children and adults in a school community. New York, NY: Oxford University Press.

Sánchez-Aroca, M. (1999). La Verneda-Sant Martí: A school where people dare to dream. Harvard Educational Review, 69, 320-357. Retrieved from http://hepg.org/her-home/issues/harvard-educationalreviewvolume-69-issue-3/herarticle/_157.

Sen, A. (1999). Development as freedom. New York, NY: Anchor Books.

Sinha, C. (2013). The sociocultural psychology as a postformal theory of academic achievement: Interrogating formal education. International Journal of Educational Psychology, 2, 221-242. doi:10.4471/ijep.2013.25

Smyth, J., \& Wrigley, T. (2013). Living on the edge: Re-thinking poverty, class and schooling. New York, NY: Peter Lang Publishing.

Soler, M. (2001). Dialogic reading: A new understanding of the reading event (Unpublished doctoral dissertation). Harvard Graduate School of Education, Cambridge, MA.

Tellado, I., Serrano, M. A., \& Portell, D. (2013). The achieved dreams of a neighborhood. International Review of Qualitative Research, 6, 289-306. doi:10.1525/irqr.2013.6.2.289

Tran, Y. (2014). Addressing reciprocity between families and schools: Why these bridges are instrumental for students' academic success. Improving Schools, 17, 18-29. doi:10.1177/1365480213515296

Valls, R., \& Kyriakides, L. (2013). The power of interactive groups: How diversity of adults volunteering in classroom groups can promote inclusion and success for children of vulnerable minority ethnic populations. Cambridge Journal of Education, 43, 17-33. doi:10.1080/0305764X.2012.749213

Vygotsky, L. S. (1962). Thought and language. Cambridge: The MIT Press.

Vygotsky, L. S. (1978). Mind in society: The development of higher psychological processes. Cambridge, MA: Harvard University Press. 